\title{
RESEÑA BIBLIOGRAFICA
}

COOTER, Robert y ACCIARRI, Hugo A. (dirs). (2012). Introducción al análisis económico del derecho. Madrid - Santiago de Chile: Civitas-Legal PublishingThomson Reuters, 344 págs.

"Si los fabricantes y proveedores son jurídicamente responsables por los daños causados por sus productos defectuosos, ¿pasarán esos productos a tornarse más caros, pero a la vez más seguros? Si se autoriza a los acreedores hipotecarios a apropiarse de los inmuebles de sus deudores incumplidores para venderlos y asi saldar la deuda, ¿ese mecanismo incrementará los negocios en ese sector? ¿Será más efectivo para incentivar el cumplimiento de los contratos bilaterales disponer que el incumplidor sea responsable sólo por el llamado interés negativo o que lo sea también por el interés positivo, esto es, por la ganancia que su contraparte habia esperado obtener del contrato?" Estas preguntas, entre muchas otras, dan cuenta de la importancia del uso del Análisis Económico del Derecho para la comprensión de las consecuencias que las leyes, sus interpretaciones y aplicaciones, proyectan sobre la sociedad. Y para evaluar, con referencia a alguna meta considerada deseable, tales consecuencias.

Hasta 1960, los juristas académicos y los abogados, respondían a estos interrogantes sobre la base de su intuición y de información no especializada, al igual que lo hacían sus ancestros desde hacía más de dos mil años. En esa década, no obstante, surgen los primeros trabajos sistemáticos que dan inicio a este modo de aproximarse al análisis del fenómeno jurídico. El tratamiento de esas cuestiones constituye el objeto del libro "Introducción al Análisis Económico del Derecho", que dirigen y escriben, en una parte sustancial, Robert Cooter y Hugo Acciarri.

El Análisis Económico del Derecho (en adelante, “AED”) propone utilizar herramientas que emplea usualmente la teoría economía para el estudio y comprensión del sistema jurídico. En ese marco, procura analizar cuál es el efecto de las normas sobre el comportamiento de los individuos y sus consecuencias sobre el bienestar social. Para esa finalidad recurre a la estadística, la teoría de precios, el análisis costo-beneficio y la teoría de juegos y, más recientemente, a la experimentación, al big data y a los desarrollos que también emplea la economía del comportamiento, sin que exista un acuerdo suficiente sobre los límites o en su caso, las ramas, de esta disciplina. Precisamente, los autores, prefieren adscribir a una noción amplia y "débil" de AED, que permita englobar todas esas posibilida- 
des, que se aleje de cualquier adscripción ideológica e incluso, que permita, por ese tipo de carriles, el estudio de materiales jurídicos sin referencia necesaria, ni exclusiva, a objetivos de eficiencia.

La obra, como su título lo indica, persigue finalidades básicamente didácticas y expositivas, y apunta a un lector proveniente de carreras jurídicas o económicas, pero no especializado en AED. No obstante, introduce -sugiere- algunos desarrollos originales y novedosos, en los cuales los autores han tenido parte. En su transcurso, recorre de modo ameno los principales temas en los que el AED ha alcanzado desarrollo. Una particularidad notable, respecto de otros textos de la disciplina, es que no se trata de la traducción o adaptación de un texto originalmente concebido para un sistema jurídico diferente, como lo es el anglosajón, y por tanto, con aspectos difícilmente homologables con los sistemas latinoamericanos e ibéricos. Al contrario, procura estudiar temas troncales, pero con referencia a lo que tienen en común los sistemas de los países de América de habla hispana y portuguesa, España y Portugal. Ese, precisamente, es el alcance de la edición que propone Thomson Reuters a través de la actividad conjunta de sus filiales, chilena (Legal Publishing) y española (Civitas), que publican y comercializan en conjunto la obra. Desde el prólogo se advierte, en tal sentido, que se ha procurado "caracterizar toda herramienta, categoría e ideas en general, forjadas en el seno del mundo jurídico anglosajón, y moldeadas sobre sus instituciones, por referencia a sus equivalentes propios de los sistemas jurídicos continentales".

Los directores de la obra son, por un lado Robert Cooter, profesor de Derecho y Economía de la Universidad de California en Berkeley, ex presidente de la American Law and Economics Association, fundador de la Asociación Latinoamericana e Ibérica de Derecho y Economía ( $A L A C D E$ ), y una de las máximas figuras de la disciplina a nivel mundial, y Hugo A. Acciarri, Profesor de la Universidad Nacional del Sur, director del programa de Maestría en Derecho de la misma institución y actual presidente de ALACDE. Colaboran en la obra algunos de los más reconocidos especialistas en la especialidad de Latinoamérica.

A continuación del prólogo siguen ocho capítulos. En el primero Cooter y Acciarri presentan a modo de introducción las relaciones entre la economía, el derecho y sus consecuencias, para posteriormente, en el Capítulo II revisar las cuestiones relacionadas con el AED de propiedad. Una exposición didáctica del Teorema de Coase y algunos elementos de teoría de juegos son utilizados para explicar cómo las facultades que constituyen el contenido del derecho de propiedad (entendido en términos jurídicos), permiten a las partes generar ganancias de la cooperación y apropiarse de las mismas, y sugieren bajo qué condiciones cada sis- 
tema puede o no resultar eficiente. En el capítulo III, el profesor peruano -uno de los introductores del AED en Latinoamérica-, Alfredo Bullard González, presenta el AED de los contratos, centrándose en la relación entre las nociones jurídicas de la eficacia y validez del contrario, y correlacionándolas con los requisitos para que los intercambios económicos incrementen la eficiencia. Sobrevuela, a partir de allí, las nociones básicas que explican qué tipo de transacciones pueden ser objeto de un contrato y los remedios jurídicos al incumplimiento, para concluir con algunas ideas sobre la interpretación contractual y sus vicisitudes. En el capítulo IV nuevamente Hugo Acciarri expone, en este caso, las nociones básicas del AED de daños. Mediante una sucesión histórica de algunas ideas centrales sobre el tema, procura desbrozar algunos aspectos permanentes y centrales. En buena medida, esas mismas ideas coindicen con las contenidas en los capítulos introductorios de su libro específico sobre la materia: Elementos de Análisis Económico del Derecho de Daños, originalmente publicado en los Estados Unidos, con una traducción portuguesa de reciente lanzamiento y una próxima primera edición argentina, anunciada para el 2015 (Thomson Reuters). En el capítulo V, el profesor de colombiano, de las universidades del Externado y profesor visitante de la Universidad de Luisiana State, Francisco Reyes Villamillar, sintetiza lo esencial de la problemática del AED y esboza su propuesta para una regulación corporativa adecuada a una realidad social como la latinoamericana. Las consideraciones principales sobre el AED del derecho procesal y la economía de la litigación y lo que respecta al análisis económico del derecho penal son expuestas por el profesor chileno, de la Universidad Diego Portales, Rafael Mery Nieto en los capítulos VI y VII. También sus párrafos dan cuenta de algunas de sus propuestas propias, que fueron objeto de publicación en revistas de alcance internacional y materia de su brillante trayectoria en la disciplina. Por último, en el capítulo VIII, el reconocido especialista internacional sobre AED de la criminalidad organizada y la práctica judicial -entre otras áreas-, ex profesor de la Universidad de Virginia e investigador de la Universidad de Columbia, Edgardo Buscaglia, reseña las nociones básicas del AED en la práctica judicial.

El Análisis Económico del Derecho constituye, sin duda, uno de los desafíos intelectuales más importantes en el estudio del Derecho, y en las ciencias sociales en general, de las últimas décadas. Esta obra, que sobresale dentro de las producidas en el subcontinente Latinoamericano, posee dos características diferencias que la hacen particularmente valiosa. Por un lado convoca para cada uno de los temas, a quienes son, probablemente, los especialistas más caracterizados en la región. Por otro, resume en un volumen pequeño, de modo claro y ameno, un conjunto amplio de ideas profundas y las hace fácilmente accesibles, sin perder rigor y siempre, sugiriendo líneas de refinamiento que también dejan vislumbrar 
razones para adentrarse en profundidad en cada uno de esos senderos. Temas, por cierto, de la mayor relevancia en un contexto en el cual, el análisis serio de los problemas institucionales es una necesidad acuciante y razonablemente una labor previa a cualquier iniciativa operativa.

Y el derecho -como explica North, aunque con otras palabras- no es otra cosa que la materia que constituye las instituciones formales. Las únicas instituciones, por cierto, que es posible modificar de modo deliberado y razonablemente expeditivo.

Andrea Barbero 